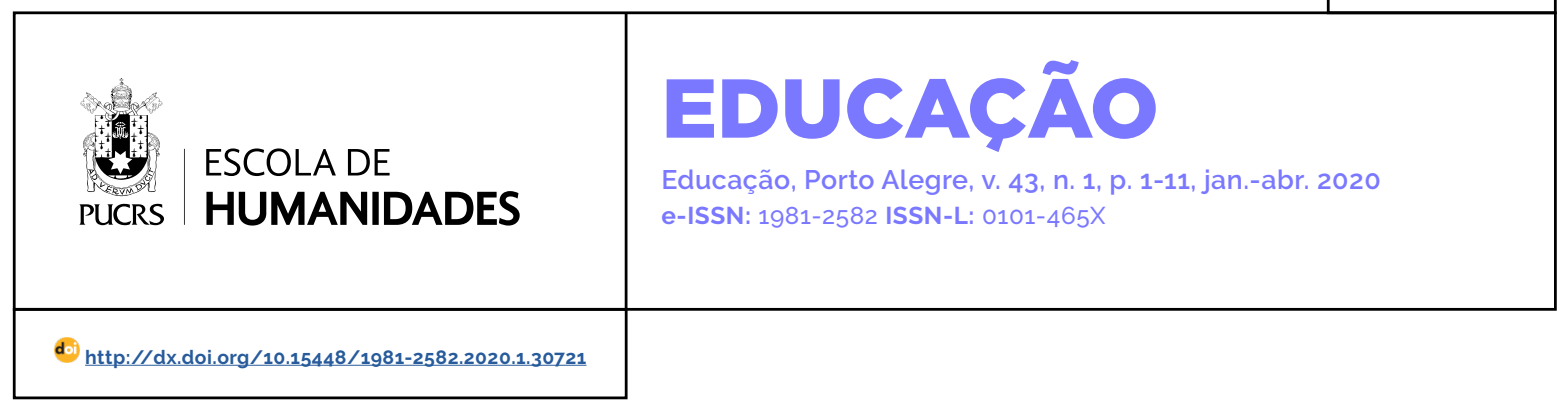

OUTROS TEMAS

\title{
Articulações sobre ética e inclusão a partir do contexto de uma Escola de Governo
}

\author{
Articulations on ethics and inclusion from the context of a School of Government \\ Articulaciones sobre ética e inclusión a partir del contexto de una Escuela de Gobierno
}

\section{Mônica Pereira dos \\ Santos $^{1}$ \\ orcid.org/0000-0002-7057-7804 \\ monicapes@gmail.com}

\section{Carolina Barreiros de \\ Lima $^{2}$ \\ orcid.org/0000-0001-7572-6859 \\ carol.barreiros.lima@gmail.com}

Renato José de Oliveira ${ }^{1}$ orcid.org/0000-0002-8071-848X rj-oliveira1958@uol.com.br

Recebido em: 20 mai. 2018. Aprovado em: 17 jan. 2020 Publicado em: 25 mai. 2020.

\section{(c) (1)}

Artigo está licenciado sob forma de uma licença Creative Commons Atribuição 4.0 Internacional.
Resumo: O presente artigo tem por objetivo compreender os sentidos atribuidos ao termo "ética" durante o processo de desenvolvimento do Index para a Inclusão em uma Escola de Governo, instituição pública que promove a formação e o aperfeiçoamento de agentes públicos. Para tanto, foram analisados dados coletados durante a pesquisa "Desenvolvendo e adaptando o Index para a Inclusão em uma Escola de Governo no Brasil", que teve por objetivo promover um processo de autorreflexão dentro da Escola e, a partir disso, propor ações que pudessem provocar transformações referentes ao desenvolvimento de culturas, políticas e práticas de inclusão institucionais. Os dados foram analisados a partir da Perspectiva Omnilética e da Teoria da Argumentação. Os resultados apontaram que os sentidos atribuídos ao termo perpassaram pelas ideias de ética como um valor "copiado": ética e inclusão: sinônimos ou à parte? e ética e sua relação com transparência.

Palavras-chave: ética, inclusão, escola de governo, perspectiva omnilética, teoria da argumentação.

Abstract: The purpose of this article is to understand the meanings attributed to the term "ethics" during the process of developing the Index for Inclusion in a School of Accounts, a public institution that promotes the training and improvement of public agents. For that, data were selected during the research "Developing and adapting the Index for Inclusion in a Government School in Brazil", which aimed to promote a process of self-reflection within the School and, from this, to propose actions that could promote changes to the development of institutional inclusion cultures, policies and practices. The data was analyzed from the Omnilectical perspective and the Theory of Argumentation. The results pointed to the following meanings attributed to ethics: as a "copied" value; ethics and inclusion: synonyms or apart? and ethics and its relationship with transparency. Keywords: ethics, inclusion, school of accounts, omnilectical perspective, theory of argumentation.

Resumen: El presente artículo tiene por objetivo comprender los sentidos atribuidos al término "ética" durante el proceso de desarrollo del Index para la Inclusión en una Escuela de Gobierno, institución pública que promueve la formación y el perfeccionamiento de agentes públicos. Para ello, se analizaron datos recogidos durante la investigación "Élaboration et adaptation de l'indice d'inclusion dans une école de gouvernement au Brésil", que tuvo por objetivo promover un proceso de autorreflexión dentro de la Escuela y, a partir de eso, proponer acciones que pudieran provocar transformaciones referentes al desarrollo de culturas, politicas y prácticas de inclusión institucionales. Los datos fueron analizados a partir de la perspectiva Omnilética y de la Teoría de la Argumentación. Los resultados apuntaron que los sentidos atribuidos al término pasaron por las ideas de ética como un valor "copiado"; ética e inclusión: sinónimos o aparte? y la ética y su relación con la transparencia.

Palabras clave: ética, inclusión, escuela de gobierno, perspectiva omnilética, teoria de la argumentación. 
Este trabalho surgiu a partir do desenvolvimento do projeto de pesquisa "Desenvolvendo e adaptando o Index para a Inclusão em uma Escola de Governo no Brasil". Tal projeto é fruto de um convênio entre o Laboratório de Pesquisas, Estudos e Apoio à Participação e à Diversidade em Educação (LaPEADE) da Faculdade de Educação da Universidade Federal do Rio de Janeiro e a Escola de Contas e Gestão do Tribunal de Contas do Estado do Rio de Janeiro (ECG/TCE-RJ) - uma Escola de Governo. O objetivo do projeto foi o de desenvolver o Index para a Inclusão (Booth \& Ainscow, 2011) nas dependências da Escola, com um grupo composto por representantes dos diversos segmentos da instituição e, quem sabe, em um movimento de multiplicação das culturas, políticas e práticas de inclusão desenvolvidos nas discussões, fortalecer os trabalhos de promoção de inclusão que vêm sendo realizados pela Escola nos últimos anos.

O Index é um material que busca promover um processo de autorrevisão dentro das instituições e propõe que esse processo se dê a partir de reflexões com base em três dimensões: a das culturas (que são os valores, aquilo em que se acredita), a das politicas (refere-se às regras, acordos e leis) e a das práticas (tudo o que fazemos e como fazemos), todas essas em uma perspectiva de promoção de inclusão. No Index, fica claro que não há como pensar em promover inclusão sem a assunção de um posicionamento ético, ideia com a qual concordamos. Inclusão, para nós, implica, necessariamente, na construção de uma ética de "combate" às diferentes formas pelas quais as exclusões são construidas e com base nas quais são justificadas.

A pesquisa foi desenvolvida ao longo do segundo semestre de 2016 e, logo após seu término, em março de 2017, um grande escândalo envolvendo o TCE-RJ veio a público. A instituição, que tem como missão fiscalizar e orientar a Administração Pública fluminense na gestão responsável dos recursos públicos, em benefício da sociedade e, como visão, fortalecer a imagem do Tribunal como instituição essencial à fiscalização e à gestão dos recursos públicos, ampliando a transparência e estimulando o controle social, estava nas manchetes dos principais jornais e telejornais brasileiros. Cinco dos sete conselheiros, incluindo o ex-presidente, foram presos, acusados de receber propina de empreiteiras que prestavam serviços para o Governo estadual.

Esse fato nos fez refletir sobre o papel que havíamos desempenhado junto a um dos braços dessa renomada instituição, a ECG. As discussões sobre inclusão promovidas com aquele grupo foram permeadas por questões éticas, pois, como dito, entendemos não ser possivel pensar inclusão sem pensar em ética.

Atualmente, em consonância com o que já afirmava Lipovetsky em 2005, a ética é um ideal que congrega e reaviva o espírito das democracias ocidentais e tem sido reconduzida a um pedestal, representando uma urgência pela qual a sociedade tem clamado. Assim, a partir do exposto, e entendendo a urgência da sociedade por uma ética na gestão pública, definimos a questão que fundamentou esse estudo: as discussões promovidas sobre inclusão refletiam, também, concepções éticas? Se sim, em que sentido(s)?

Para fins deste artigo, portanto, trabalharemos com os dados levantados na pesquisa no que se refere às evocações sobre ética e seus diferentes sentidos. Temos por propósito compreender os sentidos atribuídos ao termo "ética" pelos participantes da pesquisa acima descrita e analisá-los à luz da Perspectiva Omnilética e da Teoria da Argumentação. A partir da análise, buscamos mostrar que esses referenciais mantêm entre si uma relação de complementaridade que permite compreender os fenômenos humanosociais tanto do ponto de vista das culturas, políticas e práticas que os permeiam, quanto dos discursos que orientam e justificam as mesmas. Assim sendo, entendemos que uma análise que envolva a estreita articulação entre a Perspectiva Omnilética e a Teoria da Argumentação pode fornecer subsidios para que os sujeitos sociais desenvolvam ações voltadas para a futura transformação das situações que se colocam como desafios ou obstáculos a serem encarados. 


\section{Referencial teórico-metodológico}

\section{Perspectiva Omnilética}

Cunhada por Santos (2013), a Perspectiva Omnilética considera Inclusão como um processo cultural, político, prático, dialético e complexo. É dialético na medida em que busca pensar as contradições da realidade, o modo de compreendermos a realidade como essencialmente contraditória e em permanente transformação, um processo constante da passagem fluida de uma determinação para a outra, uma superação permanente dos contrários (Lukács, 2003), sendo, pois, as relações de inclusão e exclusão polos que necessariamente se complementam. É complexo na medida em que busca identificar elementos que de alguma forma participam do todo, se apresentando com traços do emaranhado, da desordem, da ambiguidade (Morin, 2015), nos levando a compreender que jamais conseguiremos libertar-nos da incerteza e termos um saber completo.

Além das dimensões dialética e complexidade, a Omnilética tem base nas dimensões culturais, políticas e práticas, assim como no Index para Inclusão (Booth \& Ainscow, 2011), instrumento que norteou a pesquisa aqui apresentada. Por culturas compreendemos as opiniões e as crenças que atores sociais carregam, e que vão se formando, deformando, reformando, transformando ao longo do tempo, pela história pessoal, cultural, institucional e política de cada sujeito. Políticas representam as regras e os acordos que se firmam, tácita ou explicitamente, e que objetivam operacionalizar ações. Nesse sentido, assim como normativas e leis são politicas, também o são os arranjos institucionais, grupais e pessoais que se efetivam durante os fenômenos humanos e sociais que produzem planos e decisões e almejam colocá-los em ação. As práticas são o fazer cotidiano, as ações propriamente ditas. Essas dimensões se relacionam em um movimento dialético e, ao mesmo tempo, complexo.

A título de exemplo, suponhamos a situação de uma instituição que queira promover inclusão em seu cotidiano. O próprio fato de ela querer já apontaria, em uma primeira vista, para uma cultura em que os valores de inclusão fossem desejados. No entanto, como instituições são sempre complexas, ou seja, permeadas por toda uma diversidade de fatores (histórias pessoais, valores, articulações politicas etc.), sempre haveria os que discordassem da ideia (o que apontaria para a dialética existente no contexto). Esse jogo complexo e dialético poderia resultar em uma série de possiveis "finais": a prevalência das visões de um grupo sobre outros, a construção de um consenso, a cisão dos atores sociais pertencentes àquela instituição, a permanência da situação tal e qual como estaria antes do "querer" promover inclusão, e assim por diante. De todo modo, fosse qual fosse o resultado, ele nunca seria final (já que seres humanos em jogo representam, continuamente, a possibilidade de novos rumos) e, certamente, incorreria em políticas (acordos, regras, planos de ação) e práticas as quais, por sua vez, também não seriam seguramente finais. No máximo, provisórias, temporárias.

A Perspectiva Omnilética, ao colocar essas cinco dimensões em jogo, busca, para além de respostas finais, propiciar que novos olhares sejam sempre possiveis. Em nossos estudos, (Santos, 2017; Santos, 2015) isso tem se provado algo emancipatório, posto que permite que os atores sociais envolvidos no que quer que esteja sendo foco da análise, não se vejam "sem saída", sem soluções, sem portas abertas, enfim, para que novas culturas, politicas e práticas se produzam e interajam dialética e complexamente.

\section{Teoria da Argumentação}

Em fins da década de 1950, Chaïm Perelman e Lucie Olbrechts-Tyteca, pesquisadores da Universidade Livre de Bruxelas, desenvolveram uma Teoria da Argumentação baseada em um tipo de racionalidade diferente daquela que baliza os raciocínios típicos da lógica formal. Após terem estudado por muitos anos a antiga retórica greco-romana, particularmente as obras de Aristóteles, perceberam que para estabelecer se alguma coisa é preferivel à outra e, portanto, tomar decisões e firmar escolhas, não havia que recorrer à lógica formal. Essa, parte de premissas 
indiscutivelmente verdadeiras e busca chegar a conclusões indubitáveis, parâmetros que não respondem satisfatoriamente às questões postas nos campos do Direito, da Ética, da Política etc. Tais campos do saber humano requerem o emprego de uma racionalidade mais aberta, flexivel, que leve em consideração o que é capaz de provocar (ou reforçar) a adesão das mentes às teses que lhes são apresentadas. Lograr esse objetivo implica fornecer justificativas plausiveis, visando persuadir aqueles que genericamente são chamados de auditório. Em linhas gerais, é isso o que se espera de uma boa argumentação, que empregue recursos discursivos cuja análise é objeto de estudo da teoria proposta.

\section{Ética dialógica}

Na literatura filosófica, o termo "ética" tem sido extensamente discutido. Diferentes acepções dele podem ser encontradas conforme a visão externada por diferentes escolas de pensamento. Para os racionalistas, por exemplo, a razão é a instância que possui a prerrogativa de apontar em que consiste um comportamento ético, geralmente estabelecido após o trabalho de reflexão sobre a conduta humana com base em principios norteadores. Já para os empiristas, é o costume ou hábito que leva os indivíduos e as sociedades a formularem juizos acerca do que são os comportamentos éticos. A discussão é longa e não cabe aqui detalhá-la, mas para os fins do presente trabalho adotamos a visão de Chaïm Perelman (2005): a ética dialógica. Para esse autor, tanto os princípios formais, de natureza racional, quanto os juizos práticos de base empírica podem dialogar para estabelecer o que é admitido como ético ou não. Trata-se de promover uma dialética (ou diálogo) entre os princípios e os juizos, a qual pode levar os interlocutores a encontrar soluções razoáveis para os problemas éticos em exame. O termo razoável tem o mesmo sentido de plausivel, isto é, aquilo que pode ser aceito após um processo argumentativo ter sido conduzido.

\section{Omnilética, argumentação e ética}

A partir do exposto, defendemos a ideia de que uma articulação analítica sobre os fenômenos humanos e sociais possa ser feita ao entendermos a ética presente na Teoria da Argumentação e na Perspectiva Omnilética: aquela que permite a coexistência e a dialogicidade entre juizos ou culturas; entre principios ou políticas; e a razoabilidade das soluções ou das práticas resultantes desses diálogos, que não desqualificam aprioristicamente nenhum posicionamento ou comportamento em jogo, mas que também não lhes nega a possibilidade de reconhecê-los como temporariamente inconciliável, se for o caso, e, com isso, e por isso mesmo, impulsionarem a continuidade do movimento dialógico, que também é cultural, político, prático, dialético e complexo.

\section{Metodologia}

A metodologia utilizada na pesquisa desenvolvida na ECG foi a intitulada "pesquisaação crítico-colaborativa" que, segundo a autora do projeto (Santos, 2016), possui seu alicerce na crítica emancipatória e na colaboração entre profissionais. O principal papel dos pesquisadores foi o de facilitar as reflexões e as ações ao longo dos encontros, buscando sempre a solução dos problemas levantados pela instituição colaborativamente.

A pesquisa-ação apresenta-se como uma metodologia de pesquisa qualitativa e supõe uma demanda do grupo a ser pesquisado. Para Thiollent (2002), a pesquisa-ação é centrada diretamente em uma situação ou problema coletivo no qual os participantes estão envolvidos de modo cooperativo ou participativo, o que os torna agentes em seu próprio desenvolvimento profissional. Tal abordagem metodológica pressupõe uma contínua intervenção no campo pesquisado, a partir do envolvimento dos sujeitos. Além disso, sugere mudanças, a partir da reflexão desses sujeitos. A pesquisa colaborativa, por sua vez, apresenta-se para criar uma cultura de análise das práticas realizadas, a fim de possibilitar uma transformação nas ações e práticas institucionais (Franco, 2004).

Foram realizados quinze encontros com cerca 
de duas horas de duração cada, que contaram com a participação, em média, de treze servidores representantes dos segmentos Assessoria Pedagógica, Biblioteca, Conservação e Limpeza, Coordenadoria Acadêmica, Coordenadoria de Capacitação, Coordenadoria de Documentação, Direção Geral, Docentes, Secretaria e Segurança, além das pesquisadoras.

Os encontros foram gravadose, posteriormente, transcritos, o que resultou em 789 páginas de dados coletados. Dessas 789 páginas, a palavra ética foi evocada 65 vezes, o que nos inquietou a saber em que situações essas evocações ocorreram. Para a análise e a discussão foram considerados os contextos em que essas palavras surgiram. Com relação à identidade dos sujeitos, nos respectivos contextos de fala identificados, optamos, para fins deste artigo, pela não utilização dos seus nomes reais. No entanto, objetivando contextualizar mais especificamente os trechos de falas analisados, mantivemos os cargos ocupados pelos servidores na ECG no momento da realização da pesquisa.

\section{Resultados e discussão}

Como dito, foram transcritas as mais de trinta horas de áudios gravados durante os quinze encontros realizados na Escola de Governo. Dentro dessas páginas foi possivel encontrar 65 vezes o uso da palavra ética e pretende-se aqui explorar os sentidos a ela atribuídos. Para tanto, cada uma dessas 65 evocações foi analisada em seu contexto, de forma que pudemos organizálas nas seguintes categorias de sentido: a) ética como um valor "copiado"; b) ética e inclusão: sinônimos ou à parte?; e c) ética e sua relação com transparência; todas a serem discutidas a seguir.

\section{Ética como um valor "copiado"}

As ações da Escola de Governo são norteadas por dois documentos. O primeiro deles é o Plano Estratégico (PE), documento maior e que direciona as ações de toda a instituição. O segundo é o Plano de Desenvolvimento Institucional (PDI), que estava sendo reformulado durante o desenvolvimento da pesquisa, que deve estar em consonância com o PE e refere-se especificamente às ações da Escola.

Durante a pesquisa foi realizado o processo de construção dos valores da Escola de Governo que fariam parte do novo PDI e que valeria até o ano de 2019. No PDI anterior existiam os valores sustentabilidade, efetividade, ética, qualidade, inovação, igualdade, respeito, participação, inclusão e emancipação, mas nenhum deles possuía uma definição, um significado que fosse próprio da instituição. Constavam ali apenas como palavras.

A partir das discussões levantadas e tendo como base o PE e o Index para a Inclusão, o grupo decidiu por reduzir a quantidade de valores a serem incluídos no novo PDI e por definir cada um deles. O objetivo era ficar com aqueles mais representativos do conjunto de valores dos documentos supracitados.

Enquanto se discutia a definição dos valores, iniciou-se um processo de demanda do grupo de continuar debatendo para colocar em prática os valores escolhidos após a saída da equipe de pesquisadoras. A ideia era a de que os valores fossem, de fato, representativos e estivessem presentes nas ações da Escola. A Diretora da ECG, ao discutir sobre isso, disse:

Mas isso é pra valer ou é só retórica? Porque tá lá escrito, a gente abre lá e tem afetividade e tá escrito tem atividade, não sei o quê, não sei o que lá, coisas que, pra nós, no dia a dia... A gente trabalha com esses valores? Esses valores estão presentes nas ações da escola? Eles querem dizer alguma coisa? Ou eles foram feitos lá atrás junto com a FGV, numa realidade completamente diferente do que a escola é hoje? Então, se a escola é um organismo vivo e a gente tá mudando tanta coisa, eu acho que a gente, tá, tem que repensar e talvez a oportunidade... A gente devia fazer isso pra cada desses valores que tá lá. "Ética". O que é ética pra gente? Sustentabilidade... Alguns, a gente vai poder fazer com elas Ireferindo-se às pesquisadoras], mas os outros é a gente usar essa metodologia pra conseguir continuar trabalhando, né... Internalizar esses valores é fundamental.

E um professor da ECG responde:

Internalizar esses valores é fundamental pro alinhamento inclusivo da organização. 
Uma das pesquisadoras contribui:

Semana passada, você deu a ideia de colocar na parede da escola esses valores.

A Diretora continua:

Esse é um desejo antigo. Há um ano que a gente está tentando fazer, não sei se a gente já pediu ajuda da CCS ICoordenadoria de Comunicação Social, Imprensa e Editoração]... Pra.... A gente tá pegando esses valores e a Inês tá fazendo uma arte pra botar nas paredes, assim, "inclusão", "sustentabilidade", "igualdade", mas a gente discutir também esses valores, para pensar: "Vem cá, mas a gente vai botar na parede uma coisa que não quer dizer nada pra gente?" Ou então, se alguém falar, por que tá escrito ética aqui? Ahh porque aqui na escola, ética, para nós, ética é isso...

Um professor da instituição pergunta:

E como é que vocês implantam isso?

Diretora responde:

Não, a gente copiou isso da missão do TCU que todo mundo copia igual. [Risos...]

É possivel perceber a existência de uma tensão entre dizer o que se faz e fazer o que se diz, isso é, um conflito entre palavras e atos, entre políticas e práticas. A Diretora pontua que a cultura institucional deveria corresponder à política, pois ela acredita que a internalização dos valores é importante para que as práticas reflitam tais valores. Parece-nos que ela quis dizer que se os valores institucionais não estão internalizados nos servidores, não estão presentes em suas culturas, não adianta publicar ou falar. Tal fato nos leva a crer que há, implicitamente, uma concepção instaurada de que políticas e culturas têm que estar coerentes para que as práticas aconteçam.

Refletindo omnileticamente, pode-se dizer que se as dimensões políticas e culturais estiverem coerentes é melhor e a chance de que as práticas se façam é maior, mas não necessariamente. Há pessoas, por exemplo, que agem eticamente (ou sem ética), independente da política expressa e da cultura institucional. A perspectiva Omnilética e a análise pela sua vertente nos apontam que há um movimento de contradição entre as dimensões, não sendo necessariamente condição que duas dimensões estejam coerentes entre si para que a terceira aconteça.

Quando o grupo se dá conta de que os valores institucionais foram copiados, ele percebe também o quanto as "portas" para uma mudança institucional estavam fechadas. E as portas estavam fechadas justamente porque nunca havia ocorrido uma discussão e uma reflexão coletiva entre os servidores da Escola. A análise Omnilética se apresenta como uma metodologia interessante exatamente por buscar compreender as nuances que estão em jogo, que não são imediatamente visiveis, mas que nos permitem a abertura dessas novas portas, criando novos patamares de percepção e de compreensão dos fenômenos (Santos, 2013).

Com base na teoria da argumentação, podemos dizer que o discurso da diretora põe em relevo uma ruptura de ligação entre teoria e prática no contexto de trabalho. Sendo a ligação entre elas algo que, notadamente, contribui para o êxito do fazer pedagógico. A separação ou a ruptura indicada remete a uma situação que precisaria ser encarada. Caso contrário, pode-se produzir um "faz de conta" que reflete apenas uma obrigação institucional, qual seja, a de se pautar pela ética (dimensão política) sem que se conheça efetivamente o seu significado (culturas) no plano das ações educativas cotidianas (práticas). Ademais, sendo o "faz de conta" um juizo de tipo pragmático (dimensão Omnilética das culturas), assimilado a partir do costume (práticas) de que certas coisas no interior da instituição não podem ser mudadas, a dialética com os princípios éticos formais (politicas) acaba por ser deixada de lado.

A partir, então, da tomada de consciência por parte do grupo, outros fatores poderão acontecer na instituição e, de fato, aconteceram. Talvez não tenha sido por acaso que uma diretora que se dá conta da questão aqui apontada e quer mexer nisso tenha sido exonerada logo depois do desenvolvimento do projeto de pesquisa. Outro fator que cabe destacar é que é possivel especular que, a partir desse momento da pesquisa, os 
servidores tiveram mais condição de definir seus valores, sendo possivel que eles os verbalizassem como políticas ou os demonstrassem em suas ações, em suas práticas, pois compreenderam que o valor "ética", por exemplo, precisava adquirir materialidade. Quando os participantes do encontro riram, eles perceberam que há uma lacuna e que eles iriam precisar preenchê-la. Essa lacuna é a porta aberta da complexidade.

Para saber o que isso irá resultar seria preciso retomar o contato com a instituição, o que não foi possivel até então. No entanto, gostariamos de apostar que, mesmo a diretora da Escola tendo saído, alguma mudança no sentido de uma maior preocupação com aspectos vinculados à inclusão enquanto princípios eivados de ética ocorreu na ECG a partir das discussões realizadas.

\section{Ética e inclusão: sinônimos ou à parte?}

A temática da inclusão também esteve diretamente relacionada com as discussões sobre ética. Entendemos que inclusão refere-se ao respeito às diferenças (Santos, 2000), diferenças essas que todos temos, que se manifestam pelas deficiências, pela cor da pele, pela condição social, pela aparência física, pela orientação sexual, pelas formas de pensarmos, de vestirmos, de vivermos e tantas outras, e que são comumente usadas como justificativa para a promoção de relações de exclusão. Aqui, assumimos, portanto, inclusão no sentido de respeito, acolhimento e consideração pelas diferenças e como forma de combate a tudo que justifique práticas discriminatórias, preconceituosas e excludentes. O que requer, necessariamente, em nosso ver, uma postura ética.

Nessa perspectiva, uma servidora da Coordenadoria de Estudos e Pesquisas da ECG, durante a discussão sobre a definição do valor "Inclusão" para a escola, colocou:

Eu tiraria a "Ética" e colocaria como um valor à parte. "Inclusão", assim, numa olhada rápida, tá ligada à "Igualdade, Respeito e Participação". Mas, a "Ética" é maior, ou mais forte. A palavra, o peso é mais forte e ela tem que constar também como valor à parte. Eu acho. Na minha opinião. Assim. Está ligado, mas a "Ética" tem que ser mais. Tem que ser mais valo- rizada. Ainda mais no momento atual Ireferindo-se ao processo de investigação por corrupção por que passava o Tribunal Estadual de Contas naquele momento], assim, é a sensação que me dá.

Os debates realizados foram pautados na importância de o valor ética ser considerado um valor isolado, com uma definição própria, ou, se tamanha a sua importância, deveria estar presente em todos os outros valores que o grupo decidisse adotar para o novo PDI. Uma parte do grupo defendia a ideia de ética ser mais "forte" do que qualquer outro valor e, outra parte, defendia que, justamente por essa "força", é que ela deveria estar presente em todas as outras definições a serem construidas.

Após a discussão apresentada, o grupo decidiu que "ética" deveria fazer parte das definições de todos os outros valores institucionais. No entanto, ao final dos trabalhos, dos quatro valores escolhidos para fazerem parte do PDI (sustentabilidade, inclusão, efetividade e transparência), apenas três (inclusão, efetividade e transparência) tiveram o termo "ética" inserido em seus textos.

O argumento que ganhou a adesão majoritária do grupo (auditório) pode ser caracterizado, segundo Perelman e Obrechts-Tyteca (2005), como um argumento que promove a solidariedade entre as partes (culturas, políticas e práticas presentes na instituição) e o todo maior (ético e omnilético). No caso em tela, podemos dizer que esse argumento se ancora na perspectiva de que o PDI só pode ser efetivo se tal solidariedade for respeitada, isto é, se o todo (ética) permear cada uma de suas partes, vindo a se manifestar na compreensão e na consequente aplicação de cada valor institucional considerado relevante. Para que isso ocorra de modo mais efetivo, é necessário, porém, estimularo diálogo entre as políticas institucionais (tidos como principios norteadores) e os juizos particulares (ou, pela Omnilética, culturas) que os membros do grupo cultivam, seja a partir do vivido no ambiente de trabalho, seja fora dele.

Pensando omnileticamente, o grupo reconhece a importância da ética, mas esquece de colocála em um dos textos após terem decidido que deveria constar em todos, o que aponta para uma possivel contradição em relação à força com a 
qual defendem ética. Por outro lado, o próprio fato de a ética não ter entrado em um dos valores pode significar que pelo menos para parte do grupo ele realmente se sustenta como um valor em si mesmo. Culturalmente falando, isso tem a ver com o próprio pensar a ética como um valor em si mesmo ou não; politicamente falando, se coloca ética em um texto à parte ou no meio dos outros; e na prática, o que foi realizado efetivamente, foi que tanto se colocou a ética nos outros valores institucionais, quanto não se colocou, o que ocorreu porque a contradição existente abriu essas duas "portas". O movimento omnilético nos permitiu concluir que os participantes da pesquisa chegaram em um caminho duplo.

A análise Omnilética aponta caminhos e não coisas prontas. Além disso, sua dimensão complexa coincide com uma parte de incerteza, seja proveniente dos limites de nosso entendimento, seja inscrita nos fenômenos (Morin, 2015, p. 35). Assim, não temos como saber o que realmente vem acontecendo na instituição desde então, mas podemos inferir que, ao menos quando se pensar em inclusão, efetividade e transparência, a questão ética apareça em destaque. Além disso, se esses valores, como pensados à época da pesquisa, de fato estiverem orientando, hoje, a rotina e as ações da escola, isso significa que a ética está presente em, pelo menos, um terço das rotinas institucionais. Isso, ressalvadas, evidentemente, as novas posições dialéticas e complexas entre as culturas, as políticas e as práticas, como a Omnilética nos leva a pensar.

A fim de verificar se as alterações propostas ao longo da pesquisa no que se refere ao PDI foram realizadas, buscamos o documento no site da Escola, mas não o encontramos, o que nos leva a concluir essa análise com o seguinte questionamento: será que o valor transparência, elencado pelo grupo como primordial às ações da ECG, está de fato permeando as culturas, as políticas e as práticas institucionais? Gostariamos de crer que sim!

\section{Ética e sua relação com transparência}

Como dito, o valor transparência foi um dos elencados pelo grupo como um dos mais representativos da Escola. E a ética, também permeou o debate de definição desse conceito, como pode ser visto a seguir, quando um servidor que trabalha na Direção Geral diz:

Se a gente substituisse a ideia de..., nesse valor a ideia de "transparência" pelo de "ética"...Porque eu acho assim... eu tava lendo, tipo: "ética para a ECG significa estar aberto ao diálogo dando visibilidade, prestando informações à sociedade de forma acessivel". Isso requer que demonstremos a nossa postura, comportamento transparente, de forma clara, possibilitando a formação de juizo de valor a respeito dos atos de Gestão Pública. A ética está ligada à apresentação de conteúdo atualizado, pertinente, consoante uma Gestão Pública em nossos cursos, garantindo comunicação ampla e espaços para trocas.

Uma funcionária da Coordenadoria Acadêmica concorda:

Eu concordo também. É melhor a gente substituir o nome do valor. (...) Transparência. A ética envolve a transparência.

\section{A Diretora retruca:}

Mas eu acho que essa primeira frase, aí, eu acho que ela é totalmente de transparência, porque: "Dar visibilidade e prestar informação", não necessariamente... (...) Prá mim, eu acho, prá Ec linterrompendo ao meio a palavra ECG]... "ética" não é a mesma coisa que "transparência". "Transparência" é dar visibilidade. A gente pode dar visibilidade, inclusive, de uma coisa que seja não ética, entendeu? É nesse sentido só. Que eu acho que "ética" é mais... é mais um.

A servidora atuante na Coordenadoria Acadêmica corrobora com a ideia:

É mais que transparência. O que ela tá sugerindo, eu também concordo. É deixar "ética", como mais um valor.

O servidor que trabalha na Direção Geral pondera:

É, porque assim, prá mim, a "ética" e "transparência", elas ficam junto... 
A Diretora brinca:

Pode fazer valor conjunto?

A pesquisadora que dinamiza as discussões do dia entra na brincadeira:

Pode. Transparética... [risos]

\section{A Diretora continua:}

Etiquência... Etirência. Etiqrência. [E os demais participantes da pesquisa continuaram brincando com a combinação das duas palavras]

Por fim, o grupo escolheu e definiu o valor transparência que, para a ECG, significa:

\begin{abstract}
estar aberta ao diálogo, dando visibilidade e prestando informações à sociedade, de forma acessivel. Isto requer que demonstremos nossa postura e comportamento ético de forma clara, possibilitando a formação de juizos de valor a respeito dos atos de gestão pública. A transparência está ligada à apresentação de um conteúdo atualizado, pertinente e consonante com a gestão pública em nossos cursos, garantindo comunicação ampla e espaços para trocas
\end{abstract}

Como pode ser visto, o diálogo trouxe uma discussão sobre o grau de vinculação entre ética e transparência. Um dos servidores colocou que a ética necessariamente implica a transparência, inclusive a transparência de si mesmo, ou seja, para uma pessoa ser transparente, ela tem que ser embutida de uma postura ética. Isso é o que o servidor diz acreditar (o que representa a dimensão das culturas), defender como princípio norteador (o que representa a dimensão das políticas) e praticar. A diretora, por sua vez, diz que há uma diferença entre ser transparente e ser ético, demonstrando em sua fala que concorda com o que foi dito pelo servidor, mas apontando que pode existir, por exemplo, transparência daquilo que é politicamente incorreto, portanto, antiético. Ela usou esse argumento para defender a separação entre os valores, pois acredita que toda pessoa ética é transparente, mas nem toda transparência é ética.

A partir do olhar omnilético, não houve exatamente uma tensão de posições no diálogo apresentado, não chegou a ser uma contradição, mas houve diferenças. Foram posições diferentes, embora não necessariamente contraditórias. A visão da diretora deixou a "porta" aberta para que a transparência não fosse considerada, necessariamente, ética. Quando ela trouxe, esse contraponto, o grupo argumentou, discutiu e visualizou que a abertura dessa porta estava no "transparética" ou na "etiquência". Isso ocorreu porque as diferentes visões estavam em jogo, mas buscou-se um consenso que incorporou as duas posições e a definição final do valor transparência apontou para isso. Não se separou os valores, mas também não se deixou de separá-los na medida em que a definição final de transparência contém um trecho sobre ética, sendo um desfecho bem representativo da ideia de "portas" abertas.

De acordo com a teoria da argumentação há duas modalidades genéricas de diálogo. A primeira é a erística (o termo é derivado de Eris, deusa grega da discórdia), na qual cada interlocutor se preocupa em fazer prevalecer o seu ponto de vista. A segunda é a heuristica (o termo é derivado do francês heuristique e tem o significado de procura, de descoberta) e se pauta pela busca do triunfo da melhor razão com base nos melhores argumentos. No diálogo aqui apresentado, os interlocutores inicialmente explicitaram divergências e buscaram mostrar a prevalência dos respectivos pontos de vista (modalidade erística). Entretanto, o desfecho foi notadamente de tipo heurístico, o que fica evidenciado em função do consenso produzido pelo neologismo "transparética". Embora diga respeito a um tipo de relação (a que se dá entre ética e transparência) existente em um contexto maior de relações, a construção do neologismo resultou de um processo dialético por meio do qual foi produzida uma sintese entre os principios de natureza mais formal ou institucional e os juizos particulares dos membros do grupo.

Assim, não tivemos um embate duro, mas posições diferenciadas em jogo. Nesse caso houve uma conjunção, um consenso. Isso representa o teor complexo nesse olhar tanto 
da teoria da argumentação quanto da perspectiva Omnilética, sendo interessante colocar culturas, políticas e práticas o tempo todo em jogos de lógicas contrárias, mas um jogo polilógico que vai permitir que as saidas se apresentem.

Ademais, a partir da perspectiva Omnilética, da Argumentação e da ética dialógica, parecenos relevante o resultado a que chegou o grupo quanto à definição final do valor transparência, pois a mesma incorporou um elemento a mais, o da ética, que, se efetivamente posto em prática no serviço público, só traria vantagens. Responderia, inclusive, à pergunta colocada anteriormente, sobre se o valor transparência, elencado pelo grupo como primordial às ações da ECG, estaria, de fato, permeando as culturas, as políticas e as práticas institucionais. Parecer-nos-ia que sim, na medida em que não se pode pensar inclusão sem ética, muito menos ética sem inclusão. E, como ambas, ética e inclusão, são sentidos associados ao valor transparência, poderiamos inferir que, a partir de sua nova definição, a transparência permearia, necessariamente, as culturas, as políticas e as práticas institucionais, ainda que com o foco, como explícito na definição final, em suas práticas imediatas: os cursos e os programas de formação oferecidos.

De todo modo, cumpre dizer que a simples preocupação, manifesta pelo valor explicitado em documento de tal monta já é, em si mesmo, um importante passo quando se tratam de práticas, culturas e politicas de serviços públicos.

\section{Conclusões}

O Brasil vive um momento político conturbado, com uma crise política, econômica e moral instaurada. A Escola participante desta pesquisa é um dos braços de uma instituição responsável pela fiscalização e pelo controle dos gastos públicos. Tal Escola é um órgão responsável pela formação, capacitação e especialização dos servidores públicos dos $91^{3}$ municípios sob sua jurisdição. Reflexões sobre ética nesse contexto se mostram essenciais na medida em que representam um trabalho que busca atender ao que cremos ser anseios de uma população que, particularmente, nos dias atuais, se mostra tão desacreditada na administração pública. É visivel, ainda, as dificuldades na definição de um conceito de ética em uma instituição pública de uma sociedade marcada por conflitos de valores e interesses.

Assim, a análise realizada nos permitiu identificar que os sentidos atribuidos ao termo perpassaram pelas ideias de ética como um valor "copiado"; ética e inclusão: sinônimos ou à parte? e ética e sua relação com transparência.

O sentido de ética como um valor "copiado" mostrou-nos uma preocupação da instituição com a implementação de uma cultura sobre o tema, uma cultura que efetivamente fizesse sentido para aqueles sujeitos e não estivesse apenas em uma política documental escrita há anos e que foi sendo plagiada ao longo do tempo para os demais documentos. O segundo sentido identificado, ética e inclusão: sinônimos ou à parte?, por sua vez, nos revelou o elevado nível de importância que os servidores e, portanto, a ECG, atribuem ao tema, o que está em consonância com o que acreditamos que a sociedade espera da instituição. O terceiro sentido desvelado, ética e sua relação com transparência, demonstrou a estreita relação existente entre a ética e a visibilidade, sobretudo em um contexto como o pesquisado, onde prestar informações à sociedade e ser transparente vincula-se à ideia de uma instituição ética no sentido moral do termo.

Como vimos, tais sentidos foram analisados à luz da Perspectiva Omnilética e da Teoria da Argumentação, que incorpora a noção de ética dialógica. As duas últimas nos permitiram examinar o material discursivo sob o prisma das razões ou motivos invocados para ganhar a adesão dos membros do grupo (auditório), quer para a crítica ao já instituido, quer para as perspectivas de solução anunciadas. A Omnilética, por sua vez, nos permitiu identificar em que medida a ética se refletiu nas discussões promovidas sobre inclusão, sempre a partir de um olhar com foco nas cinco dimensões: culturas, políticas, práticas, dialética e complexidade.

\footnotetext{
3 O município da capital do estado possui seu próprio Tribunal Municipal de Contas, motivo pelo qual não faz parte dos 91 municipios abordados pelo TCE.
} 
As deduções obtidas sobre os sentidos atribuidos ao termo "ética" durante os debates sobre "inclusão", a partir da relação de complementaridade entre a Perspectiva Omnilética e a Teoria da Argumentação, nos permitiram a identificação de uma contribuição de análise que consideramos ampla. Além disso, nesta visão mais alargada, tal análise apresenta-se, ainda, como uma possibilidade para a promoção de mudanças nas situações excludentes que precisam ser encaradas.

\section{Referências}

Booth, T., \& Ainscow, M. (2011). Index para Inclusão: desenvolvendo a aprendizagem e a participação na escola (M. P. dos Santos, Trad.). Produzido pelo Laboratório de Pesquisa, Estudos e Apoio à Participação e à Diversidade em Educação (LaPEADE). Reimpressão.

Franco, M. A. R. S. A (2004). Pedagogia da pesquisa-ação. In Encontro Nacional de Didática e Prática de Ensino, 12. Curitiba. Anais. Curitiba: Endipe.

Lukács, G. (2003). História da Consciência de Classe: Estudos sobre a dialética marxista. São Paulo: Martins Fontes.

Morin, E. (2015). Introdução ao pensamento complexo (4 ${ }^{\mathrm{a}}$. Ed). Porto Alegre: Sulina.

Perelman, C., \& Olbrechts-Tyteca, L. (2005). Tratado da argumentação. A nova retórica (2a . ed.). São Paulo Martins Fontes

Perelman, C. (2005). Ética e direito (2a . Ed). São Paulo: Martins Fontes.

Santos, M. P. (2013). Dialogando sobre inclusão em educação: Contando casos (e descasos). (1. ed.). Curitiba, PR: CRV.

Santos, M. P. (2015). Inclusão, direitos humanos e interculturalidade: uma tessitura omnilética. In P. A. de Castro (Org.). Inovação, Ciência e Tecnologia: Ddesafios e perspectivas na contemporaneidade (pp. 49-66). Campina Grande: Realize.

Santos, M. P. (2016). Projeto Desenvolvendo e Adaptando o Index para a Inclusão em Uma Escola de Governo no Brasil: Apresentado à Plataforma Brasil. (Parecer número 1.738.778).

Santos, M. P, \& Frazão, L.P. (2000). Inclusão: Respeito às diferenças. Cadernos Pestalozzi, 2(3), 155-163.

Santos, M. P., Melo, S. C. de, Santiago, M. C., \&Nazareth, P. (2017, March). Inclusion in public administration: Developing the concept of inclusion within a school of accounts and administration. International Journal of Educational Administration and Policy Studies, Vol.9(3), 35-46. https://doi.org/10.5897/IJEAPS2017.0504.
Thiollent, M. (2002). Metodologia da pesquisa-ação (11 ${ }^{\mathrm{a}}$. ed.). São Paulo, SP: Cortez.

\section{Mônica Pereira dos Santos}

Doutora em Psicologia e Educação Especial pelo Institute of Education da Universidade de Londres - UL, Mestre em Psicologia e Educação Especial pelo Institute of Education da Universidade de Londres - UL. Professora associada da Faculdade de Educação da Universidade Federal do Rio de Janeiro - UFRJ, coordenadora do Grupo de Pesquisa, Estudos e Apoio à Participação e à Diversidade em Educação (LaPEADE).

\section{Carolina Barreiros de Lima}

Mestre em Educação pela Universidade Federal do Rio de Janeiro - UFRJ, licenciada em Matemática pela Universidade Federal do Rio de Janeiro - UFRJ. Assessora do Instituto de Educação Roberto Bernardes Barroso - IERBB/MPRJ.

\section{Renato José de Oliveira}

Doutor em Educação pela Pontificia Universidade Católica do Rio de Janeiro - PUC-RJ, Mestre em Educação pela Fundação Getúlio Vargas do Rio de Janeiro - FGV-RJ, graduado em Engenharia Química pela Universidade do Estado do Rio de Janeiro - UERJ e licenciado em Química pela Universidade do Estado do Rio de Janeiro - UERJ. Professor titular da Universidade Federal do Rio de Janeiro - UFRJ.

\section{Endereço para correspondência}

Mônica Pereira dos Santos

Universidade Federal do Rio de Janeiro

Av. Pedro Calmon, 550 - Cidade Universitária

Rio de Janeiro - RJ, 21941-901 